\title{
Learning Through Experience
}

\section{Loisa Bennetto}

Department of Clinical and Social Psychology

It has only been a few years since I began my career in academia. As I look back at my first semester at the University of Rochester, I remember feeling fairly confident about how to organize my research program. I knew how to set up my lab, design experiments, recruit subjects, and analyze data. These skills were, after all, the focus of my training in graduate school. But I also realized that I was going to spend a large portion of my time teaching and that in all my years of graduate school, no one had really taught me how to be a teacher. It took me about one semester to realize I was wrong. The goal of teaching was not to teach, it was to help someone learn. And I had certainly had a great deal of experience in learning. The challenge then was to translate my experience as a student into the classroom.

I teach psychology. During the past several years, I have taught courses that range from large core-level lectures to specialized seminars to applied internships. These courses have focused generally on psychopathology-the study of atypical human behavior-and more specifically on developmental disabilities. While my specific goals may vary by course and context, my overall teaching goals remain essentially the same. As a teacher, I focus on giving my students the tools for learning on their own, an appreciation for integrating information across disciplines, and opportunities to apply their knowledge both in the classroom and in real world settings.

\section{Tools for learning}

Learning is a process, not an end point. Much of the factual information I teach in my courses will change, or at least be qual- 
ified over the next decade as our understanding of psychopathology and disabilities improves. Furthermore, most people who have access to a library or the Internet can find many of the facts that I review in my courses. The more important and challenging goal, then, is to help students learn to use their knowledge to understand, critique, discover new ideas and relationships, and ask new questions. Unlike the specific facts, these tools for learning will never become outdated.

Some of the strategies I use to help students acquire these tools are best illustrated in my undergraduate seminar on the Psychology of Developmental Disabilities. This course addresses the main concepts and issues involved in the identification, treatment, education, and support of children and adults with mental retardation and other developmental disabilities. I have yet to find a textbook that even begins to cover the range of relevant information that impacts this field. This provides an excellent opportunity to help students look for answers and new questions in less obvious places. For example, it is impossible to understand the experience of individuals with disabilities without being able to observe and learn from them in their own environments. For one assignment, students in this seminar visit different community settings that serve individuals with disabilities, and critically evaluate how the practices in these settings fit and do not fit with what they have been studying in the classroom. Depending on their interests, students spend time with individuals whose ages range from preschool to adulthood, and in settings that include educational, vocational, residential, and diagnostic centers. For example, this past year, students' visits included a preschool for children with autism, a residential group home for adults with developmental disabilities, and a diagnostic clinic for children with attention-deficit/hyperactivity disorder. By comparing their experiences in different settings, students develop their own understanding of why certain practices (such as inclusion) can work well in one context, yet be inappropriate in another.

Another tool for learning is the ability to critically evaluate current research and treatment programs. In seminar discussions, students often generate new avenues for intervention to improve the lives of individuals with disabilities. I have found that students' desire to improve existing services and quality of 
life becomes an ideal motivation to foster their interest in research. The final project in this course involves writing a mock grant proposal for an intervention program for individuals with disabilities. Students learn to evaluate existing intervention programs, design a comprehensive yet focused program of their own, and identify and circumvent logistical barriers to the implementation of their ideas. After spending a few days in the library, many students come to tell me that there are no published studies that have addressed their particular topic. This provides the additional opportunity for students to learn to integrate information from different areas or disciplines to answer their unique questions.

\section{Integration across disciplines}

My research focuses on the neuropsychology of developmental disabilities. Working in this field requires a familiarity with current theory and research from several disciplines, such as clinical psychology, developmental psychology, cognitive science, neurology, genetics, and special education. Being able to utilize and integrate new findings from different fields is part of what makes this research so exciting. As a teacher, I continually look for ways to help students integrate their learning across courses. By approaching their undergraduate years as a connected experience, rather than a series of distinct classes, students will remember and be able to apply a much greater proportion of the information they learned.

Each spring, I teach the introductory course on Abnormal Psychology. This is an intriguing topic, as well as a requirement for many of the psychology programs, so I tend to have students whose interests span many different fields. While many of these students will become psychology majors, others' interests will lead them to choose another concentration. One of my goals is to engage these non-psychology students so they can take the information and perspectives from my course back to their major. At the same time, my course will be more meaningful if they can apply what they already know to the study of atypical behavior.

A large part of helping students integrate information is knowing who they are. I need to know how students will be using, or think they will be using, the information they learn in my class. I also need to consider how the information from my 
course can best be incorporated into students' existing knowledge schemas. While these questions are relatively easy to answer in the context of a small seminar, it is much harder to identify the specific interests and needs of an entire lecture hall of students. Recently, I began using undergraduate teaching assistants as a link to the students in my Abnormal Psychology class. Although I meet and learn about individual students through my office hours and e-mail, I have found that the undergraduate TAs have an excellent understanding of their peers' interests and concerns as a group. Through our weekly meetings, the TAs have helped me shape my lectures and assignments so they are more accessible to a broader range of students.

Another illustration of the need to foster ties between fields comes from my graduate course on the Neurobiological Foundations of Behavior. This seminar is primarily for graduate students in our Clinical Psychology program, many of whom have a relatively limited background in neurobiology. Not only do they express concerns about being able to understand the subject matter, but they also wonder how it will relate to their long-term clinical and research goals. This course is extremely enjoyable for me to teach because of the ongoing challenge of helping students find the connections between each basic science topic and their research and clinical interests. For example, in the class on neurotransmitters, I direct our discussion to highlight the path from neurochemistry to psychopharmacology to strategies for providing support to psychotherapy patients who are concerned about the effectiveness of their psychiatric medications. By drawing attention to how neurobiology overlaps with clinical psychology, students are less intimidated by the subject matter and more likely to see how they can apply this knowledge to other aspects of their careers.

\section{Applications of knowledge}

Unfortunately, students may not find opportunities to use much of what they learn until months or even years after a course is over. The chance to apply knowledge as it is being learned is infinitely more rewarding - it gives students a forum to explore their new ideas, an incentive to shape the course of their academic pursuits, and the benefit of seeing firsthand the impact of their education. 
As a teacher, I try to provide both formal and informal opportunities for students to apply what they are learning. In my lectures and seminars, I design written assignments that help students see the impact of societal perceptions on psychopathology and disability, and begin to consider how they can use their knowledge to promote more accurate and beneficial attitudes. For example, students in my Abnormal Psychology course write a paper that examines the portrayal of psychopathology in popular films. They consider how these representations affect individuals with mental illness through both public and personal prejudice, agency-level support, diagnostic trends, and access to services. This assignment also gives students the opportunity to practice their diagnostic skills, and an informal but meaningful forum to discuss what they are learning with their peers outside of class.

The best opportunities for students to apply their knowledge, however, are through internships in the community. For the past three years, I have been coordinating a unique internship experience for students who are interested in developmental disabilities. This internship began in a somewhat unusual classroom on the University of Rochester campus. This classroom is run by the New York Board of Cooperative Educational Services (BOCES), and provides educational training for 18- to 21-year-old individuals with developmental disabilities. It was specifically designed to provide a more integrative and age-appropriate setting for older students with disabilities who are still being served by the school system. In addition, it provides a powerful learning experience for our students at the University of Rochester, through internships, classroom visits, and countless opportunities for less formal interaction.

University of Rochester interns spend approximately 10 hours a week with the BOCES class, where they gain firsthand knowledge of specific disabilities and the special education system, and learn to design and implement a range of academic, functional, and community-based activities. This is a unique setting, since the students in the BOCES class are roughly the same age as the interns. The similarities between the two groups provide opportunities for meaningful and natural interactions, and also help interns develop a very clear understanding of the specific challenges of having a developmental disability. 
Over the past several semesters, this internship has evolved from a traditional experience where students came to me for individual supervision to a more formal course with weekly group meetings where students can learn from each other. I have also expanded the number of internship sites to increase opportunities for training and to help students consider how their specific internship experience might apply to other settings and groups of individuals with disabilities. For example, this past semester interns were placed in the classroom for young adults on the University of Rochester campus, several preschool and schoolaged classrooms for children with autism and for children with multiple physical and developmental disabilities, and a vocational and recreational program for adults with disabilities which was housed on a working farm. Students also participated in an intern exchange program, where they spent a day at one of their classmates' sites and saw firsthand what they had been hearing about during our group discussions. Our weekly meetings were meaningful learning opportunities because students now had real experiences they could bring to help themselves and each other understand new issues. For example, the interns formulated theories about lifespan developmental changes in autism by comparing the preschoolers, school-aged children, and adults with autism they met at their different placements.

This internship not only provides students with the opportunity to use their knowledge, but also to experience firsthand the bidirectional relationship between theory and application. Because of the specialized and intimate nature of this course, however, internship positions are limited. While this is frustrating for me as a teacher, the long-range benefits of the internship are becoming more apparent. This past spring, University of Rochester undergraduates and students in the BOCES classroom worked together to organize and play an exhibition basketball game. The game was played by students from the classroom, and coached by two members of the men's basketball team, one of whom had previously been an intern. The coaches worked with students each week to teach them the rules of the game, build their athletic skills, and promote their sense of sportsmanship. The game was played in the Alexander Palestra, just as the varsity games are. The coaches' teammates and members of the women's team helped to announce, referee, run the scoreboard, and cheer the 
players. While I expected my interns would attend, I was excited about the number of people from the University community who heard about the game and came to support the BOCES teams. My students have started to become teachers themselves, by providing their peers with opportunities to learn and expand their perspectives. 